\title{
Improved Finite Beam Element Method to Analyze the Natural Vibration of Steel-Concrete Composite Truss Beam
}

\author{
Zhipeng Lai, ${ }^{1,2}$ Lizhong Jiang, ${ }^{1,2}$ Wangbao Zhou, ${ }^{1,2}$ and Xilin Chai ${ }^{1}$ \\ ${ }^{1}$ School of Civil Engineering, Central South University, Changsha 410075, China \\ ${ }^{2}$ National Engineering Laboratory for High Speed Railway Construction, Changsha 410075, China \\ Correspondence should be addressed to Wangbao Zhou; zhouwangbao@163.com
}

Received 30 April 2017; Accepted 18 July 2017; Published 22 August 2017

Academic Editor: Nerio Tullini

Copyright (c) 2017 Zhipeng Lai et al. This is an open access article distributed under the Creative Commons Attribution License, which permits unrestricted use, distribution, and reproduction in any medium, provided the original work is properly cited.

\begin{abstract}
Based on Hamilton's principle, this study has developed a continuous treatment for the steel-concrete composite truss beam (SCCTB). It has also deduced the SCCTB element stiffness matrix and mass matrix, which include the effects of interface slip, shear deformation, moment of inertia, and many other influencing factors. A finite beam element method (FBEM) program for SCCTB's natural vibration frequency has been developed and used to calculate the natural vibration frequencies of several SCCTBs with different spans and different degrees of shear connections. The FBEM's calculation results of several SCCTBs agree well with the results obtained from ANSYS. Based on the results of this study, the following conclusions can be drawn. For the SCCTB with high-order natural vibration frequency and with short span, the effect of the shear deformation is greater. Hence, the effect of the shear deformation on the SCCTB's high-order natural vibration frequency cannot be ignored. On the other hand, the effect of the interface slip on the SCCTB's high-order natural vibration frequency is insignificant. However, the effect of the interface slip on the SCCTB's low-order natural vibration frequency cannot be ignored.
\end{abstract}

\section{Introduction}

The SCCTB is a new-type structural member. It is developed on the basis of ordinary composite beams and uses shear connectors to connect the concrete slab to the steel truss into one entire joint work. Comparing with ordinary truss beams, SCCTB is more effective because it uses both the compressive strength of concrete and the tensile strength of steel. Hence, it is characterized by high utilization rate of indoor space, high economic efficiency, high bending stiffness, and high bearing capacity $[1,2]$.

Even though a beam is designed as a full composite section, due to the deformation of shear studs, it cannot respond with perfect composite action without slip. Further, unlike Euler-Bernoulli beams in which there is infinite shear stiffness, it may not be appropriate to design other beams by neglecting the shear deformation of the concrete slab and steel truss beam, for example, composite beams with a small span-to-depth ratio [3-6]. Therefore, the natural vibration characteristics of SCCTBs are affected by the coupled effects of the shear deformation and the interfacial slip between the concrete slab and steel truss beam.

Hitherto, there are many studies on the shear behavior of hybrid steel-trussed-concrete beams, which are constructed by embedding the prefabricated steel trusses into a concrete core cast in situ. On the other hand, there are few studies on the mechanical properties of SCCTB. Using the software ABAQUS to carry out the finite element (FE) numerical simulations, Monaco [7] investigated the shear behavior of hybrid steel-trussed-concrete beams. Monti and Petrone [8] developed the shear capacity equations from a purposely developed mechanics-based shear model for hybrid steeltrussed-concrete beams. Campione et al. [9] investigated a calculation method for the prediction of the shear resistance of precast composite beam; both experimental and numerical results were used to validate the developed analytical expressions.

Giltner and Kassimali [10] developed a method which can replace the trusses and the beam elements with an equivalent beam, thereby reducing the size of the computer model for 
analysis. Machacek and Cudejko [11, 12] investigated the distribution of longitudinal shear along the interface between the steel and the concrete of various composite truss bridges from the elastic phase to the plastic collapse. He found that the nonlinear distribution of the longitudinal shear significantly depends on the rigidity of the shear connection and the densification of the shear connectors above the truss nodes. By carrying out an experimental study and a theoretical analysis, Chan and Fong [13] concluded that the use of the effective length method in the linear analysis and design method was less convenient and less accurate than the second-order analysis. On the basis of the literature [13], Fong et al. [14] further showed that the second-order analysis method was not only an accurate design method, but it can also avoid the uncertain approximate value of the effective length. By comparing the results from the finite element numerical calculation method with the experimental results, Bujnak and Bouchair [15] found that the local effects of the concentrated longitudinal shear forces should be examined in SCCTB. Siekierski [16] analyzed the effects of the shrinkage of concrete slab in SCCTB and developed a set of linear equations to compute the axial forces in the flange members of the truss girder and the transverse shear forces in SCCTB.

The natural vibration characteristic analysis is the basis to investigate the dynamic characteristics of SCCTB. So, it is necessary to investigate its natural vibration characteristics. As shown by the earlier studies, the mechanical properties of SCCTB are affected by the interface slip, shear deformation, moment of inertia, and many other factors. However, there are only a few studies on the SCCTB's natural vibration characteristics which have taken these factors into account. In this study, a continuous treatment for SCCTB has been developed. It has also deduced the SCCTB element stiffness matrix and mass matrix with the cubic Hermite polynomial shape function, which includes the effects of the interface slip, shear deformation, moment of inertia, and many other influencing factors. Hence, even with fewer degrees of freedom, the precision in the calculation is satisfactory. Based on the developed SCCTB element, this study has developed a FBEM program which can calculate the natural vibration frequency of SCCTBs commonly used in the engineering practice. Finally, it calculates the natural vibration frequencies of several SCCTBs with different spans and different degrees of shear connections. Based on the results of the analyses, some conclusions which are related to the engineering design are drawn.

\section{Cross-Sectional Analysis of Strain and Stress of SCCTB}

2.1. Displacement Model of SCCTB. In Figure $1, H_{3}, T_{3}, h_{3}$, and $t_{3}$ are the height and width of the external and internal walls of the upper chord, respectively; $H_{4}, T_{4}, h_{4}$, and $t_{4}$ are the height and width of the external and internal walls of the lower chord, respectively; $H_{5}, T_{5}, h_{5}$, and $t_{5}$ are the height and width of external and internal walls of the oblique web member, respectively; $H_{6}, T_{6}, h_{6}$, and $t_{6}$ are the height and width of the external and internal walls of the vertical

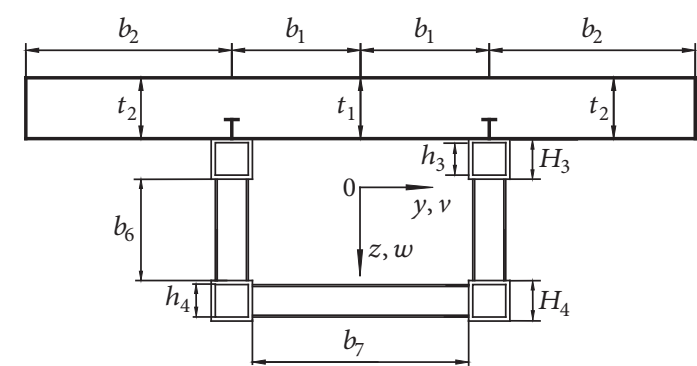

FIgURE 1: Sectional dimension and the coordinate system of the SCCTB.

web member, respectively; $H_{7}, T_{7}, h_{7}$, and $t_{7}$ are the height and width of the external and internal walls of the lower horizontal connection member, respectively; $H_{8}, T_{8}, h_{8}$, and $t_{8}$ are the height and width of the external and internal walls of the oblique bracing member, respectively; $t_{1}$ and $t_{2}$ are the thicknesses of the concrete roof and the cantilever slabs, respectively; $2 b_{1}$ and $b_{2}$ are the widths of the concrete roof and the cantilever slabs, respectively; and $b_{3}, b_{4}, b_{5}, b_{6}, b_{7}$, and $b_{8}$ are the lengths of the upper chord, lower chord, oblique web member, vertical web member, lower horizontal connection member, and oblique bracing member, respectively.

The strain of oblique bracing member can be expressed as

$$
\varepsilon_{b_{8}}=\frac{\Delta_{b_{8}}}{b_{8}}=\frac{\Delta_{b_{4}} \cos \beta}{b_{4} / \cos \beta}=\frac{\Delta_{b_{4}} \cos ^{2} \beta}{b_{4}}=\varepsilon_{x 4} \cos ^{2} \beta,
$$

where $\beta$ is the angle between lower horizontal connection member and oblique bracing member, $\Delta_{b_{8}}$ is the axial displacement of the oblique bracing member, and $\Delta_{b_{4}}$ is the axial displacement of the lower chord.

Further, the axial force of the oblique bracing member is given by

$$
F_{b_{8}}=E_{s} \varepsilon_{b_{8}} A_{8}=E_{s} \varepsilon_{x 4} A_{8} \cos ^{2} \beta .
$$

The longitudinal component of the axial force of the oblique bracing member is given by

$$
F_{p x}=F_{b_{8}} \cos \beta=E_{s} \varepsilon_{x 4} A_{8} \cos ^{3} \beta .
$$

Therefore, the longitudinal equivalent area of the oblique bracing member can be expressed as follows:

$$
A_{8 H}=A_{8} \cos ^{3} \beta=A_{8} \cos ^{3} \beta .
$$

The longitudinal displacement of SCCTB can be expressed as follows [17]:

$$
\begin{aligned}
u_{i}(x, y, z) & = \begin{cases}k_{c} \xi(x)-\left(z-z_{c}\right) \theta(x) & i=1,2 \\
k_{s} \xi(x)-\left(z-z_{s}\right) \theta(x) & i=3,4\end{cases} \\
k_{c} & =-\frac{A_{s}}{A_{0}} \\
k_{s} & =\frac{A_{c}}{\left(n A_{0}\right)}
\end{aligned}
$$


where $z_{s}$ is the $z$-coordinate of the centroid of the steel truss beam; $z_{c}$ is the $z$-coordinate of the centroid of the concrete slab; $\theta(x)=w^{\prime}(x)-\gamma_{w}(x)$ is the cross-sectional rotation angle; $w(x)$ is the vertical deflection of the SCCTB; $\xi(x)$ is the difference between the longitudinal displacement of the concrete slab centroid and that of the steel truss beam centroid; $E_{s}$ is the elastic modulus of the steel truss and $E_{c}$ is the elastic modulus of the concrete slab. Further, $n=$ $E_{s} / E_{c} ; A_{c}=A_{1}+A_{2} ; A_{s}=A_{3}+A_{4}+A_{8 H} ; A_{0}=A_{c} / n+$ $A_{s} ; A_{1}=2 b_{1} t_{1} ; A_{2}=2 b_{2} t_{2} ; \quad A_{3}=2\left(H_{3} T_{3}-h_{3} t_{3}\right) ; A_{4}=$ $2\left(H_{4} T_{4}-h_{4} t_{4}\right) ; A_{5}=2\left(H_{5} T_{5}-h_{5} t_{5}\right) ;$ and $A_{8}=H_{8} T_{8}-h_{8} t_{8}$.

The axial displacement of the oblique web member is given by

$$
\begin{aligned}
\Delta_{5} & =\delta_{1} \cos \alpha, \\
\delta_{1} & =b_{4}\left(w^{\prime}-\theta\right),
\end{aligned}
$$

where $\alpha$ is the angle between the oblique and vertical web members.

2.2. Strain Model of SCCTB. According to the displacement model of SCCTB in Section 2.1, the longitudinal strain of the cross-section can be expressed as

$$
\begin{aligned}
& \varepsilon_{x i}=\frac{\partial u_{i}}{\partial x}= \begin{cases}k_{c} \xi^{\prime}-\left(z-z_{c}\right) \theta^{\prime} & i=1,2 \\
k_{s} \xi^{\prime}-\left(z-z_{s}\right) \theta^{\prime} & i=3,4,\end{cases} \\
& \gamma_{w}=w^{\prime}-\theta, \\
& \varepsilon_{f x}=\frac{\Delta_{5}}{b_{5}}=\frac{b_{4}\left(w^{\prime}-\theta\right) \cos \alpha}{b_{5}}=\frac{b_{4} b_{6}}{b_{5}{ }^{2}}\left(w^{\prime}-\theta\right),
\end{aligned}
$$

where $\varepsilon_{x i}(i=1,2,3,4)$ are the longitudinal strains of the top slab, cantilever slab, upper chord, and lower chord, respectively; $\varepsilon_{f x}$ is the normal strain of the oblique web member.

Derived from (5), the longitudinal relative $\operatorname{sip} \zeta(x, t)$ between the concrete slab and the truss is

$$
\zeta(x, t)=\xi+h_{c} \theta+h_{s} \theta=\xi+h \theta,
$$

where $h=h_{c}+h_{s} ; h_{c}$ and $h_{s}$ are the distances from the centroids of the concrete slab and steel truss to the interface, respectively.

2.3. Stress Model of SCCTB. Based on the strain models of SCCTB in Section 2.2, the stresses of SCCTB are

$$
\begin{aligned}
\sigma_{x i} & = \begin{cases}E_{c}\left[k_{c} \xi^{\prime}-\left(z-z_{c}\right) \theta^{\prime}\right] & i=1,2 \\
E_{s}\left[k_{s} \xi^{\prime}-\left(z-z_{s}\right) \theta^{\prime}\right] & i=3,4,\end{cases} \\
\tau_{w} & =G_{s}\left(w^{\prime}-\theta\right), \\
\sigma_{f x} & =E_{s} \frac{b_{4} b_{6}}{b_{5}{ }^{2}}\left(w^{\prime}-\theta\right),
\end{aligned}
$$

where $\sigma_{x i}(i=1,2,3,4)$ are the longitudinal stresses of the top slab, cantilever slab, upper chord, and lower chord, respectively; $\tau_{w}$ is the shear stress of the upper chord and the lower chord, respectively; and $\sigma_{f x}$ is the normal stress of the oblique web member. by

The shearing force per unit length of the interface is given

$$
\begin{aligned}
\varsigma(x, t) & =k_{s l} \zeta(x, t)=k_{s l}(\xi+h \theta), \\
k_{s l} & =K_{1} / l_{s}, \\
K_{1} & =0.66 n_{s} V_{u}, \\
V_{u} & =\frac{A_{s} f_{s} r l_{s}}{\left(L n_{s}\right)},
\end{aligned}
$$

where $k_{s l}$ is the longitudinal shear stiffness in per unit length between the concrete slab and the steel truss beam and the unit is $\mathrm{N} / \mathrm{mm}^{2} ; K_{1}$ is the longitudinal shear stiffness of the shear connections, and the unit is $\mathrm{N} / \mathrm{mm} ; n_{s}$ is the number of shear connections in a crosswise row; $l_{s}$ is the longitudinal spacing between two studs; $L$ is the effective span of SCCTB; $r$ is the degree of shear connection; $f_{s}$ is the yield strength of steel material; and $V_{u}$ is the shear strength of the stud.

\section{Finite Beam Element Method of SCCTB}

3.1. Improved SCCTB Element Stiffness Matrix and Mass Matrix Including the Effects of Interface Slip and Shear Deformation. In order to satisfy the consistency requirements, for the different displacement functions to contribute to the same strain function, the degree of polynomial has to be the same after the finite element approximation. Otherwise, there are unreal geometric constraint conditions, which can significantly reduce the accuracy of the finite element method and result in shear locking $[5,18]$. The highest-order derivatives of each displacement function in (8)-(11) show that the highest derivatives of $\xi(x)$ and $\theta(x)$ are first-order derivatives. Hence, the corresponding shape function can only satisfy the continuity condition for $C^{0}$. Further, (9) shows that the shape function of the deflection function $w(x)$ must satisfy the continuity condition of $C^{1}$. According to the principle of numerical calculation, in order to satisfy the continuity condition of $C^{1}$, the Hermite polynomial has to be at least cubic. However, (9) shows that the contribution of the deflection function $w(x)$ to the cross-section rotation function $\theta(x)$ is a quadratic polynomial. Hence, in order to satisfy the consistency requirements, the displacement functions $\xi(x)$ and $\theta(x)$ have to be approximated using the quadratic polynomials. Further, the elements satisfying the consistency requirements have to have at least 10 degrees of freedom, as shown in Figure 2. Assume that the nodal displacement vector is

$$
\begin{gathered}
\xi(x)=\varphi_{\xi} \mathbf{q}_{\xi}, \\
\theta(x)=\varphi_{\theta} \mathbf{q}_{\theta}, \\
w(x)=\varphi_{w} \mathbf{q}_{w},
\end{gathered}
$$




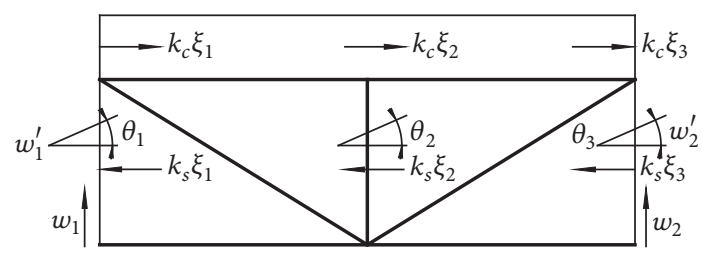

FIGURE 2: Nodal degrees of freedom of the SCCTB element.

$$
\begin{aligned}
\mathbf{q}_{\xi} & =\left[\xi_{1}, \xi_{2}, \xi_{3}\right]^{T}, \\
\mathbf{q}_{\theta} & =\left[\theta_{1}, \theta_{2}, \theta_{3}\right]^{T}, \\
\mathbf{q}_{w} & =\left[w_{1}, w_{1}^{\prime}, w_{2}, w_{2}^{\prime}\right]^{T} .
\end{aligned}
$$

The Hermite polynomial shape function to satisfy the continuity condition of $C^{1}$ at the element boundary is

$$
\begin{aligned}
\varphi_{\xi} & =\varphi_{\theta}=\left[1-3 k+2 k^{2}, 4 k-4 k^{2},-k+2 k^{2}\right] \\
\varphi_{w} & =\left[1-3 k^{2}+2 k^{3},\left(k-2 k^{2}+k^{3}\right) l, 3 k^{2}\right. \\
& \left.-2 k^{3}, l\left(-k^{2}+k^{3}\right)\right],
\end{aligned}
$$

where $k=x / l$ and $l$ is the element length.

Substituting (15) into (8) gives

$$
\begin{aligned}
\varepsilon_{x i} & = \begin{cases}k_{c} \varphi_{\xi}^{\prime} \mathbf{q}_{\xi}-\left(z-z_{c}\right) \varphi_{\theta}^{\prime} \mathbf{q}_{\theta} & i=1,2 \\
k_{s} \varphi_{\xi}^{\prime} \mathbf{q}_{\xi}-\left(z-z_{s}\right) \varphi_{\theta}^{\prime} \mathbf{q}_{\theta} & i=3,4\end{cases} \\
\gamma_{w} & =\varphi_{w}^{\prime} \mathbf{q}_{w}-\varphi_{\theta} \mathbf{q}_{\theta}, \\
\zeta(x) & =\varphi_{\xi} \mathbf{q}_{\xi}+h \varphi_{\theta} \mathbf{q}_{\theta}, \\
\varepsilon_{f x} & =\frac{b_{4} b_{6}}{b_{5}{ }^{2}}\left(\varphi_{w}^{\prime} \mathbf{q}_{w}-\varphi_{\theta} \mathbf{q}_{\theta}\right) .
\end{aligned}
$$

Substituting (15) into (12)-(13) gives

$$
\begin{aligned}
\sigma_{x i} & = \begin{cases}E_{c}\left[k_{c} \varphi_{\xi}^{\prime} \mathbf{q}_{\xi}-\left(z-z_{c}\right) \varphi_{\theta}^{\prime} \mathbf{q}_{\theta}\right] & i=1,2 \\
E_{s}\left[k_{s} \varphi_{\xi}^{\prime} \mathbf{q}_{\xi}-\left(z-z_{s}\right) \varphi_{\theta}^{\prime} \mathbf{q}_{\theta}\right] & i=3,4\end{cases} \\
\tau_{w} & =G_{s}\left(\varphi_{w}^{\prime} \mathbf{q}_{w}-\varphi_{\theta} \mathbf{q}_{\theta}\right), \\
\varsigma(x) & =k_{s l}\left(\varphi_{\xi} \mathbf{q}_{\xi}+h \varphi_{\theta} \mathbf{q}_{\theta}\right), \\
\sigma_{f x} & =E_{s} \frac{b_{4} b_{6}}{b_{5}{ }^{2}}\left(\varphi_{w}^{\prime} \mathbf{q}_{w}-\varphi_{\theta} \mathbf{q}_{\theta}\right) .
\end{aligned}
$$

The kinetic energy of the SCCTB can be expressed as

$$
\begin{aligned}
T= & \frac{1}{2} \int_{l} m \dot{w}^{2} d x+\frac{1}{2} \sum_{i=1}^{4} \int_{l} \int_{A_{i}} \rho_{i} \dot{u}_{i}^{2} d A d x \\
& +\frac{1}{2} \int_{l} \int_{A_{5}} \rho_{s} \dot{u}_{i}^{2} \frac{b_{5}}{b_{4}} d A d x+\frac{1}{2} \int_{l} \int_{A_{8}} \frac{\rho_{s} \dot{u}^{2}}{\cos \beta} d A d x,
\end{aligned}
$$

where $m=\rho_{c} A_{c}+\rho_{s} A_{s} ; \rho_{c}$ and $\rho_{s}$ are the densities of the steel material and the concrete material, respectively; and $\rho_{1}=\rho_{2}=\rho_{c}, \rho_{3}=\rho_{4}=\rho_{s}$.

The strain energy of SCCTB can be expressed as

$$
\begin{aligned}
V & =\frac{1}{2} \int_{l}\left(\sum_{i=1}^{4} \int_{A_{i}} \sigma_{x i} \varepsilon_{x i} d A+\int_{A_{x g}} \tau_{w} \gamma_{w} d A\right. \\
& \left.+\int_{A_{e q}} \sigma_{f x} \varepsilon_{f x} d A+\int_{A_{8 H}} \sigma_{x 4} \varepsilon_{x 4} d A+\varsigma \zeta\right) d x
\end{aligned}
$$

where $A_{e q}=A_{5} / \sin \alpha$ and $A_{x g}=A_{3}+A_{4}$.

According to (22) and (23), the variation forms of the strain energy and the kinetic energy can be expressed as

$$
\begin{aligned}
& \int_{t_{1}}^{t_{2}} \delta T d t=-\int_{t_{1}}^{t_{2}}\left[m \int_{l} \ddot{w} \delta w d x\right. \\
& \quad+\int_{l}\left(\int_{A_{c}} \rho_{c} \ddot{u}_{c} \delta u_{c} d A+\int_{A_{x g}} \rho_{s} \ddot{u}_{s} \delta u_{s} d A\right) d x \\
& \quad+\int_{l} \int_{A_{e q}} \rho_{s} \ddot{u}_{s} \delta u_{s} d A d x \\
& \left.\quad+\int_{l} \int_{A_{8}} \frac{1}{\cos \beta} \rho_{s} \ddot{u}_{s} \delta u_{s} d A d x\right] d t \\
& \quad \delta V d t=\int_{t_{1}}^{t_{2}}\left[\int_{l} \int_{A_{c}} \delta \varepsilon_{x}^{T} \sigma_{x} d A d x\right. \\
& \quad+\int_{l} \int_{A_{x g}}\left(\delta \varepsilon_{x}^{T} \sigma_{x}+\delta \gamma_{w}^{T} \tau_{w}\right) d A d x \\
& \quad+\int_{l} \int_{A_{5}} \frac{1}{\sin \alpha} \delta \varepsilon_{f x}^{T} \sigma_{f x} d A d x \\
& \left.\quad+\int_{l} \int_{A_{8 H}} \delta \varepsilon_{x 4}^{T} \sigma_{x 4} d A d x+\int_{l} \delta \zeta^{T} \varsigma d x\right] d t .
\end{aligned}
$$

By substituting (18)-(20) into (24), the SCCTB element mass matrix is

$$
\begin{aligned}
\mathbf{M}_{e}= & {\left[\begin{array}{lll}
\mathbf{M}_{\xi \xi} & \mathbf{M}_{\xi \theta} & \mathbf{M}_{\xi w} \\
\mathbf{M}_{\theta \xi} & \mathbf{M}_{\theta \theta} & \mathbf{M}_{\theta w} \\
\mathbf{M}_{w \xi} & \mathbf{M}_{w \theta} & \mathbf{M}_{w w}
\end{array}\right], } \\
\mathbf{M}_{\xi \xi}= & \int_{l} \int_{A_{c}} \rho_{c} k_{c}^{2} \varphi_{\xi}^{T} \varphi_{\xi} d A d x \\
& +\int_{l} \int_{A_{x g}} \rho_{s} k_{s}^{2} \varphi_{\xi}^{T} \varphi_{\xi} d A d x \\
& +\int_{l} \int_{A_{e q}} \rho_{s} k_{s}^{2} \varphi_{\xi}^{T} \varphi_{\xi} d A d x \\
& +\int_{l} \int_{A_{8}} \frac{1}{\cos \beta} \rho_{s} k_{s}^{2} \varphi_{\xi}^{T} \varphi_{\xi} d A d x,
\end{aligned}
$$




$$
\begin{aligned}
& \mathbf{M}_{\xi \theta}=\int_{l} \int_{A_{c}} \rho_{c} k_{c} z_{1} \varphi_{\xi}^{T} \varphi_{\theta} d A d x \\
& +\int_{l} \int_{A_{x g}} \rho_{s} k_{s} z_{2} \varphi_{\xi}^{T} \varphi_{\theta} d A d x \\
& +\int_{l} \int_{A_{e q}} \rho_{s} k_{s} z_{2} \varphi_{\xi}^{T} \varphi_{\theta} d A d x \\
& +\int_{l} \int_{A_{8}} \frac{1}{\cos \beta} \rho_{s} k_{s} z_{2} \varphi_{\xi}^{T} \varphi_{\theta} d A d x, \\
& \mathbf{M}_{\theta \theta}=\int_{l} \int_{A_{c}} \rho_{c} z_{1}^{2} \varphi_{\theta}^{T} \varphi_{\theta} d A d x \\
& +\int_{l} \int_{A_{x g}} \rho_{s} z_{2}^{2} \varphi_{\theta}^{T} \varphi_{\theta} d A d x \\
& +\int_{l} \int_{A_{e q}} \rho_{s} z_{2}^{2} \varphi_{\theta}^{T} \varphi_{\theta} d A d x \\
& +\int_{l} \int_{A_{8}} \frac{1}{\cos \beta} \rho_{s} z_{2}^{2} \varphi_{\theta}^{T} \varphi_{\theta} d A d x, \\
& \mathbf{M}_{\xi w}=\mathbf{0}, \\
& \mathbf{M}_{\theta w}=\mathbf{0} \text {, } \\
& \mathbf{M}_{w w}=m \int_{l} \varphi_{w}{ }^{T} \varphi_{w} d x, \\
& \mathbf{M}_{\theta \xi}=\mathbf{M}_{\xi \theta}^{T}, \\
& \mathbf{M}_{w \xi}=\mathbf{M}_{\xi w}^{T}, \\
& \mathbf{M}_{w \theta}=\mathbf{M}_{\theta w}^{T},
\end{aligned}
$$

where $m=m_{1}+m_{2}+m_{3}+m_{4}+m_{5}+m_{6}+m_{7}+m_{8} ; m_{1}=\rho_{c} A_{1}$; $m_{2}=\rho_{c} A_{2} ; m_{3}=\rho_{s} A_{3} ; m_{4}=\rho_{s} A_{4} ; m_{5}=\rho_{s} A_{5} b_{5} / b_{4} ; m_{6}=$ $\rho_{s} b_{6} A_{6} / b_{4} ; m_{7}=\rho_{s} b_{7} A_{7} / b_{4} ; m_{8}=\rho_{s} A_{8} b_{8} / b_{4} ; k_{1}=k_{2}=k_{c} ;$ $k_{3}=k_{4}=k_{s} ; z_{1}=z_{c}-z ; z_{2}=z_{s}-z$.

By substituting (18)-(20) into (25), the SCCTB element stiffness matrix is

$$
\begin{aligned}
\mathbf{K}_{e}= & {\left[\begin{array}{ccc}
\mathbf{K}_{\xi \xi} & \mathbf{K}_{\xi \theta} & \mathbf{K}_{\xi w} \\
\mathbf{K}_{\theta \xi} & \mathbf{K}_{\theta \theta} & \mathbf{K}_{\theta w} \\
\mathbf{K}_{w \xi} & \mathbf{K}_{w \theta} & \mathbf{K}_{w w}
\end{array}\right], } \\
\mathbf{K}_{\xi \xi}= & \int_{l} \int_{A_{c}} E_{c} k_{c}^{2} \varphi_{\xi}^{\prime T} \varphi_{\xi}^{\prime} d A d x \\
& +\int_{l} \int_{A_{x g}} E_{s} k_{s}^{2} \varphi_{\xi}^{\prime T} \varphi_{\xi}^{\prime} d A d x \\
& +\int_{l} \int_{A_{8}} E_{s} k_{s}^{2} \varphi_{\xi}^{\prime T} \varphi_{\xi}^{\prime} \cos ^{3} \beta d A d x \\
& +\int_{l} k_{s l} \varphi_{\xi}^{T} \varphi_{\xi} d x,
\end{aligned}
$$

$$
\begin{aligned}
\mathbf{K}_{\xi \theta}= & \int_{l} \int_{A_{c}} E_{c} k_{c} z_{1} \varphi_{\xi}^{\prime T} \varphi_{\theta}^{\prime} d A d x \\
& +\int_{l} \int_{A_{x g}} E_{s} k_{s} z_{2} \varphi_{\xi}^{\prime T} \varphi_{\theta}^{\prime} d A d x \\
& +\int_{l} \int_{A_{8}} E_{s} k_{s} z_{2} \varphi_{\xi}^{\prime T} \varphi_{\theta}^{\prime} \cos ^{3} \beta d A d x \\
& +\int_{l} \varphi_{\xi}^{T} k_{s l} h \varphi_{\theta} d x, \\
\mathbf{K}_{\theta \theta}= & \int_{l} \int_{A_{c}} z_{1}^{2} E_{c} \varphi_{\theta}^{\prime T} \varphi_{\theta}^{\prime} d A d x \\
& +\int_{l} \int_{A_{x g}}\left(z_{2}^{2} E_{s} \varphi_{\theta}^{\prime T} \varphi_{\theta}^{\prime}+G_{s} \varphi_{\theta}^{T} \varphi_{\theta}\right) d A d x \\
& +\int_{l} \int_{A_{5}} \frac{b_{4} b_{6}^{2}}{b_{5}^{3}} E_{s} \varphi_{\theta}^{T} \varphi_{\theta} d A d x \\
& +\int_{l} \int_{A_{8}} z_{2}^{2} E_{s} \varphi_{\theta}^{\prime T} \varphi_{\theta}^{\prime} \cos ^{3} \beta d A d x \\
& +\int_{l} h^{2} k_{s l} \varphi_{\theta}^{T} \varphi_{\theta} d x,
\end{aligned}
$$$$
\mathbf{K}_{\theta w}=\int_{l} \int_{A_{5}}\left(-\frac{b_{4} b_{6}^{2}}{b_{5}^{3}} E_{s} \varphi_{\theta}^{T} \varphi_{w}^{\prime}\right) d A d x
$$$$
-\int_{l} \int_{A_{x g}} G_{s} \varphi_{\theta}^{T} \varphi_{w}^{\prime} d A d x
$$$$
\mathbf{K}_{w w}=\int_{l} \int_{A_{5}} \frac{b_{4} b_{6}^{2}}{b_{5}^{3}} E_{s} \varphi_{w}^{\prime T} \varphi_{w}^{\prime} d A d x
$$$$
+\int_{l} \int_{A_{x g}} G_{s} \varphi_{w}^{\prime T} \varphi_{w}^{\prime} d A d x
$$$$
\mathbf{K}_{\xi w}=\mathbf{0}
$$$$
\mathbf{K}_{\theta \xi}=\mathbf{K}_{\xi \theta}^{T},
$$$$
\mathbf{K}_{w \xi}=\mathbf{K}_{\xi w}^{T},
$$$$
\mathbf{K}_{w \theta}=\mathbf{K}_{w \theta}^{T} .
$$

3.2. Solving the Natural Vibration Frequency of SCCTB. Based on the SCCTB element stiffness matrix $\mathbf{K}_{e}$, element mass matrix $\mathbf{M}_{e}$, and element displacement vector $\mathbf{q}_{e}=$ $\left\{\mathbf{q}_{\xi}^{T}, \mathbf{q}_{\theta}^{T}, \mathbf{q}_{w}^{T}\right\}^{T}$, and using the "seat by number" method, the SCCTB overall stiffness matrix $\mathbf{K}$, overall mass matrix $\mathbf{M}$, and overall degree of freedom vector $\mathbf{q}$ can be obtained. The common boundary conditions for the SCCTB can be expressed as follows $[17,19]$ :

$$
\left.\xi\right|_{x=0, L}=\left.w\right|_{x=0, L}=\left.\theta\right|_{x=0, L}=0
$$


The transformational relationship between the SCCTB overall degree of freedom vector before and after applying the boundary constraint can be expressed as follows:

$$
\mathbf{q}=\mathbf{S} \overline{\mathbf{q}},
$$

where $\mathbf{S}$ is the transformation matrix for the overall degree of freedom vector, which can be obtained for the given boundary conditions, and $\overline{\mathbf{q}}$ is the SCCTB overall degree of freedom vector after applying the boundary constraint.

The free vibration function for a structure with multiple degrees of freedom can be expressed as follows:

$$
\mathbf{M u}+\mathbf{K u}=\mathbf{0} .
$$

Let

$$
\mathbf{u}=\mathbf{q} \sin \omega t
$$

where $\omega$ is the structure's natural vibration frequency.

Substituting (31) into (30) gives

$$
\left(-\omega^{2} \mathbf{M}+\mathbf{K}\right) \mathbf{q}=\mathbf{0} .
$$

Substituting (29) into (32) gives

$$
\left(-\omega^{2} \overline{\mathbf{M}}+\overline{\mathbf{K}}\right) \overline{\mathbf{q}}=\mathbf{0},
$$

where

$$
\begin{aligned}
\overline{\mathbf{M}} & =\mathbf{S}^{T} \mathbf{M S}, \\
\overline{\mathbf{K}} & =\mathbf{S}^{T} \mathbf{K S} .
\end{aligned}
$$

Using (33), the frequency equation of SCCTB can be obtained as follows:

$$
\left|-\omega^{2} \overline{\mathbf{M}}+\overline{\mathbf{K}}\right|=0
$$

The software MATLAB has been used to develop the FBEM program of the abovementioned SCCTB element. Then, the natural vibration frequency of SCCTB has been solved by including the effects of both the interface slip and shear deformation.

3.3. Simplification of SCCTB Element Stiffness Matrix. If the shear deformation is not considered, then

$$
\begin{aligned}
\gamma_{w} & =w^{\prime}-\theta=0 \Longrightarrow \\
w^{\prime} & =\theta \Longrightarrow \\
\varphi_{w}^{\prime} \mathbf{q}_{w} & =\varphi_{\theta} \mathbf{q}_{\theta}, \\
\left.w^{\prime}\right|_{x=0} & =\left.\varphi_{w}^{\prime} \mathbf{q}_{w}\right|_{x=0}=w_{1}^{\prime}, \\
\left.w^{\prime}\right|_{x=l} & =\left.\varphi_{w}^{\prime} \mathbf{q}_{w}\right|_{x=l}=w_{2}^{\prime}, \\
\left.w^{\prime}\right|_{x=0.5 l} & =\left.\varphi_{w}^{\prime} \mathbf{q}_{w}\right|_{x=0.5 l}=\left[-\frac{3}{2 l},-\frac{1}{4}, \frac{3}{2 l},-\frac{1}{4}\right] \mathbf{q}_{w}, \\
\left.\theta\right|_{x=0} & =\left.\varphi_{\theta} \mathbf{q}_{\theta}\right|_{x=0}=\theta_{1}, \\
\left.\theta\right|_{x=0.5 l} & =\left.\varphi_{\theta} \mathbf{q}_{\theta}\right|_{x=0.5 l}=\theta_{2}, \\
\left.\theta\right|_{x=l} & =\left.\varphi_{\theta} \mathbf{q}_{\theta}\right|_{x=l}=\theta_{3} .
\end{aligned}
$$

Using (36), the following expression can be obtained:

$$
\begin{aligned}
& \theta_{1}=w_{1}^{\prime}, \\
& \theta_{2}=\left[-\frac{3}{2 l},-\frac{1}{4}, \frac{3}{2 l},-\frac{1}{4}\right] \mathbf{q}_{w}, \\
& \theta_{3}=w_{2}^{\prime} .
\end{aligned}
$$

Using (37) and excluding the effect of the shear deformation, the element stiffness matrix $\widetilde{\mathbf{K}}_{e}$ and mass matrix $\widetilde{\mathbf{M}}_{e}$ are

$$
\begin{aligned}
\widehat{\mathbf{K}}_{e} & =\mathbf{S}_{d} \mathbf{K}_{e} \mathbf{S}_{d}^{T}, \\
\widehat{\mathbf{M}}_{e} & =\mathbf{S}_{d} \mathbf{M}_{e} \mathbf{S}_{d}^{T},
\end{aligned}
$$

where $S_{d}$ is a $7 \times 10$ transformation matrix and can be obtained using (37).

After obtaining the SCCTB element stiffness matrix and mass matrix without the effect of the shear deformation, the same method in Section 3.2 can be used to calculate the natural vibration frequency of SCCTB without the effect of the shear deformation.

\section{Cases for Analyses}

To verify the accuracy of the developed FBEM (Section 3), the natural frequencies of two groups of clamped supported SCCTBs (i.e., SCCTB-1 and SCCTB-2) have been calculated using both the finite element method and the FBEM. For each group, there are cases with five degree of shear connection $(r=0.4,0.6,0.8,1.0,2.0)$ and two spans. The mechanical and geometrical parameters of the SCCTBs are as follows:

$$
\begin{aligned}
l_{s} & =25 \mathrm{~mm}, \\
n_{s} & =10, \\
b_{1} & =400 \mathrm{~mm}, \\
b_{2} & =200 \mathrm{~mm}, \\
b_{3} & =200 \mathrm{~mm}, \\
b_{4} & =200 \mathrm{~mm}, \\
b_{5} & =447.2 \mathrm{~mm}, \\
b_{6} & =400 \mathrm{~mm}, \\
b_{7} & =760 \mathrm{~mm}, \\
b_{8} & =785.9 \mathrm{~mm}, \\
t_{1} & =150 \mathrm{~mm}, \\
t_{2} & =150 \mathrm{~mm}, \\
H_{3} & =40 \mathrm{~mm}, \\
h_{3} & =34 \mathrm{~mm}, \\
H_{4} & =40 \mathrm{~mm},
\end{aligned}
$$


$h_{4}=34 \mathrm{~mm}$,

$H_{5}=43 \mathrm{~mm}$,

$h_{5}=37 \mathrm{~mm}$,

$H_{6}=22 \mathrm{~mm}$,

$h_{6}=17 \mathrm{~mm}$,

$H_{7}=22 \mathrm{~mm}$,

$h_{7}=17 \mathrm{~mm}$,

$H_{8}=22 \mathrm{~mm}$,

$h_{8}=17 \mathrm{~mm}$,

$H_{9}=22 \mathrm{~mm}$,

$h_{9}=17 \mathrm{~mm}$,

$T_{3}=40 \mathrm{~mm}$,

$t_{3}=34 \mathrm{~mm}$,

$T_{4}=40 \mathrm{~mm}$,

$t_{4}=34 \mathrm{~mm}$,

$T_{5}=43 \mathrm{~mm}$,

$t_{5}=37 \mathrm{~mm}$,

$T_{6}=22 \mathrm{~mm}$,

$t_{6}=17 \mathrm{~mm}$,

$T_{7}=22 \mathrm{~mm}$,

$t_{7}=17 \mathrm{~mm}$,

$T_{8}=22 \mathrm{~mm}$,

$t_{8}=17 \mathrm{~mm}$,

$T_{9}=22 \mathrm{~mm}$,

$t_{9}=17 \mathrm{~mm}$,

$E_{s}=2.1 \times 10^{5} \mathrm{MPa}$,

$E_{c}=4.5 \times 10^{4} \mathrm{MPa}$,

$\rho_{s}=7900 \mathrm{~kg} \cdot \mathrm{m}^{-3}$,

$\rho_{c}=2400 \mathrm{~kg} \cdot \mathrm{m}^{-3}$,

$f_{y}=400 \mathrm{MPa}$,

$\mu_{s}=0.3$,

$\mu_{c}=0.2$,

$L_{1}=10 \mathrm{~m}$,

$L_{2}=12 \mathrm{~m}$.
$L_{i}(i=1,2)$ are the calculation lengths of the two groups of SCCTBs, respectively. Further, $\mu_{s}$ and $\mu_{c}$ are Poisson's ratio of steel and concrete, respectively.

The calculations by the finite element method have been carried out using the finite element program, ANSYS. The upper chord and the lower chord have been simulated using SHELL43 shell element. The vertical web member, oblique web member, lower horizontal connection member, and oblique bracing member have been simulated using BEAM188 elements. The concrete slab has been simulated using SOLID65 solid elements. The studs have been simulated using COMBIN14 spring elements. The elastic modulus $K_{1}$ of the spring element has been calculated using (14). In the finite element models, by coupling the degrees of freedom in the vertical direction of the nodes at the same position, the interface between the concrete slab and the steel truss beam is connected in the vertical; that is, there is no vertical separation between the concrete slab and the steel truss beam. In order to simulate the clamped supported at the ends of the beams in the finite element models, there are constrains in the degrees of freedom in the vertical, transverse, and longitudinal directions.

Tables 1 and 2 show a comparison of the results of the calculated natural frequencies by the FBEM and ANSYS model. $R_{\mathrm{AN}}$ is the calculation result from the ANSYS model. $R_{\mathrm{FB}}$ is the calculation result from the FBEM including the effects of the shear deformation and the interface slip. $R_{\mathrm{SD}}$ is the calculation result without including the effect of the shear deformation. Further, $e_{\mathrm{FB}}=100\left(R_{\mathrm{FB}}-R_{\mathrm{AN}}\right) / R_{\mathrm{AN}}$ is the calculation error in FBEM, and $e_{\mathrm{SD}}=100\left(R_{\mathrm{SD}}-R_{\mathrm{FB}}\right) / R_{\mathrm{FB}}$ and $C_{s}=\left(\left.R_{\mathrm{FB}}\right|_{r=2.0}-\left.R_{\mathrm{FB}}\right|_{r=0.4}\right) /\left.R_{\mathrm{FB}}\right|_{r=2.0}$, where $e_{\mathrm{SD}}$ and $C_{s}$ are the errors due to the effects of the shear deformation and the interface slip, respectively.

From Tables 1 and 2 and Figures 3-5, the following can be seen:

(1) By including the effects of the interface slip, shear deformation, moment of inertia, and many other influencing factors on the SCCTB, the results of the FBEM's calculations agree with those of the ANSYS's finite element calculations. The maximum calculation error $e_{\mathrm{FB}}$ of the first six orders of natural vibration frequency is less than $4.6 \%$. This is an indication that the SCCTB element stiffness matrix and mass matrix developed in this study are rational and effective. According to the calculation results of ANSYS, the local vibration of SCCTB-1 with small span is becoming obvious in the 6th mode, while SCCTB-2 with larger span does not cause this kind of vibration in high modes. Neglecting local vibration will result in generating additional restraints on the SCCTB, which will overestimate the restrain rigidity of the SCCTB. The proposed FBEM model in this paper can be used to describe the actual behavior of SCCTBs in flexural vibrations effectively, but it does not take into account the local vibration. Therefore, the 6th natural frequency of SCCTB-1 using FBEM is slightly larger than the ANSYS' results.

(2) Without including the effect of the shear deformation on the SCCTB's natural vibration frequency, the FBEM's calculation results are greater than those of the ANSYS's calculations. Further, SCCTB's shear deformation effect is 
TABLE 1: Comparison of calculation results between the FBEM and ANSYS model (SCCTB-1).

\begin{tabular}{|c|c|c|c|c|c|c|c|}
\hline \multirow{2}{*}{$r$} & \multirow{2}{*}{ Computation methods } & \multicolumn{6}{|c|}{ Natural frequencies $(\mathrm{Hz})$} \\
\hline & & 1st & 2nd & 3rd & 4th & 5th & 6th \\
\hline \multirow{3}{*}{0.40} & $R_{\mathrm{AN}}$ & 9.443 & 24.192 & 44.764 & 70.425 & 100.160 & 122.580 \\
\hline & $R_{\mathrm{FB}}$ & 9.313 & 24.049 & 44.384 & 68.993 & 96.811 & 126.960 \\
\hline & $R_{\mathrm{SD}}$ & 9.706 & 26.119 & 50.630 & 83.145 & 123.639 & 172.038 \\
\hline \multirow{3}{*}{0.60} & $R_{\mathrm{AN}}$ & 9.580 & 24.359 & 44.930 & 70.570 & 100.280 & 122.610 \\
\hline & $R_{\mathrm{FB}}$ & 9.480 & 24.274 & 44.629 & 69.225 & 97.022 & 127.146 \\
\hline & $R_{\mathrm{SD}}$ & 9.895 & 26.404 & 50.977 & 83.524 & 124.037 & 172.447 \\
\hline \multirow{3}{*}{0.80} & $R_{\mathrm{AN}}$ & 9.701 & 24.512 & 45.087 & 70.709 & 100.390 & 122.630 \\
\hline & $R_{\mathrm{FB}}$ & 9.628 & 24.482 & 44.861 & 69.448 & 97.227 & 127.329 \\
\hline & $R_{\mathrm{SD}}$ & 10.064 & 26.670 & 51.311 & 83.892 & 124.427 & 172.850 \\
\hline \multirow{3}{*}{1.00} & $R_{\mathrm{AN}}$ & 9.809 & 24.653 & 45.236 & 70.844 & 100.510 & 122.660 \\
\hline & $R_{\mathrm{FB}}$ & 9.760 & 24.676 & 45.083 & 69.665 & 97.428 & 127.508 \\
\hline & $R_{\mathrm{SD}}$ & 10.216 & 26.920 & 51.631 & 84.251 & 124.810 & 173.248 \\
\hline \multirow{3}{*}{2.00} & $R_{\mathrm{AN}}$ & 10.214 & 25.236 & 45.884 & 71.454 & 101.020 & 122.770 \\
\hline & $R_{\mathrm{FB}}$ & 10.257 & 25.484 & 46.056 & 70.653 & 98.362 & 128.356 \\
\hline & $R_{\mathrm{SD}}$ & 10.790 & 27.980 & 53.066 & 85.920 & 126.630 & 175.165 \\
\hline & $C_{s}(\%)$ & 9.206 & 5.633 & 3.629 & 2.350 & 1.577 & 1.087 \\
\hline
\end{tabular}

TABLE 2: Comparison of calculation results between the FBEM and ANSYS model (SCCTB-2).

\begin{tabular}{|c|c|c|c|c|c|c|c|}
\hline \multirow{2}{*}{$r$} & \multirow{2}{*}{ Computation methods } & \multicolumn{6}{|c|}{ Natural frequencies $(\mathrm{Hz})$} \\
\hline & & 1 st & 2nd & 3rd & 4 th & 5 th & 6th \\
\hline \multirow{3}{*}{0.40} & $R_{\mathrm{AN}}$ & 6.717 & 17.314 & 32.190 & 50.824 & 72.887 & 97.708 \\
\hline & $R_{\mathrm{FB}}$ & 6.598 & 17.177 & 32.065 & 50.470 & 71.700 & 95.122 \\
\hline & $R_{\mathrm{SD}}$ & 6.795 & 18.224 & 35.278 & 57.903 & 86.098 & 119.830 \\
\hline \multirow{3}{*}{0.60} & $R_{\mathrm{AN}}$ & 6.833 & 17.465 & 32.347 & 50.966 & 73.013 & 97.813 \\
\hline & $R_{\mathrm{FB}}$ & 6.734 & 17.370 & 32.284 & 50.686 & 71.903 & 95.307 \\
\hline & $R_{\mathrm{SD}}$ & 6.944 & 18.454 & 35.562 & 58.214 & 86.427 & 120.170 \\
\hline \multirow{3}{*}{0.80} & $R_{\mathrm{AN}}$ & 6.935 & 17.602 & 32.494 & 51.103 & 73.134 & 97.915 \\
\hline & $R_{\mathrm{FB}}$ & 6.853 & 17.548 & 32.491 & 50.893 & 72.100 & 95.488 \\
\hline & $R_{\mathrm{SD}}$ & 7.075 & 18.666 & 35.832 & 58.516 & 86.750 & 120.504 \\
\hline \multirow{3}{*}{1.00} & $R_{\mathrm{AN}}$ & 7.025 & 17.729 & 32.634 & 51.235 & 73.252 & 98.014 \\
\hline & $R_{\mathrm{FB}}$ & 6.957 & 17.712 & 32.688 & 51.094 & 72.292 & 95.665 \\
\hline & $R_{\mathrm{SD}}$ & 7.190 & 18.864 & 36.090 & 58.810 & 87.065 & 120.834 \\
\hline \multirow{4}{*}{2.00} & $R_{\mathrm{AN}}$ & 7.352 & 18.242 & 33.234 & 51.826 & 73.796 & 98.481 \\
\hline & $R_{\mathrm{FB}}$ & 7.338 & 18.384 & 33.539 & 52.001 & 73.182 & 96.501 \\
\hline & $R_{\mathrm{SD}}$ & 7.612 & 19.683 & 37.228 & 60.157 & 88.549 & 122.409 \\
\hline & $C_{s}(\%)$ & 10.079 & 6.564 & 4.396 & 2.944 & 2.026 & 1.429 \\
\hline
\end{tabular}

greater for SCCTB with the high-order natural vibration frequency. If SCCTB's natural vibration frequency order is six, the shear deformation effect is $36.5 \%$. Hence, the shear deformation effect on the SCCTB's high-order natural vibration frequency cannot be ignored.

(3) For SCCTB with a shorter span, the shear deformation effect is greater.

(4) The section rotation caused by the bending moment and the shear deformation caused by the shear force both result in a bending displacement of the structural member. The shear deformation effect on SCCTB at the low-order frequency is insignificant. This is an indication that the
SCCTB's bending vibration-type of low-order is mainly due to the bending deformation caused by the section rotation and the bending deformation caused by shear deformation is small.

(5) For the shear deformation effect-natural vibration frequency order curves of SCCTB under different degrees of shear connections, they overlap with each other. This is an indication that the effect of the degree of shear connections on SCCTB's shear deformation effect is not significant. It is because the shear force of SCCTB is mainly carried by the web member of the steel truss and has little relation to the degree of shear connections. 

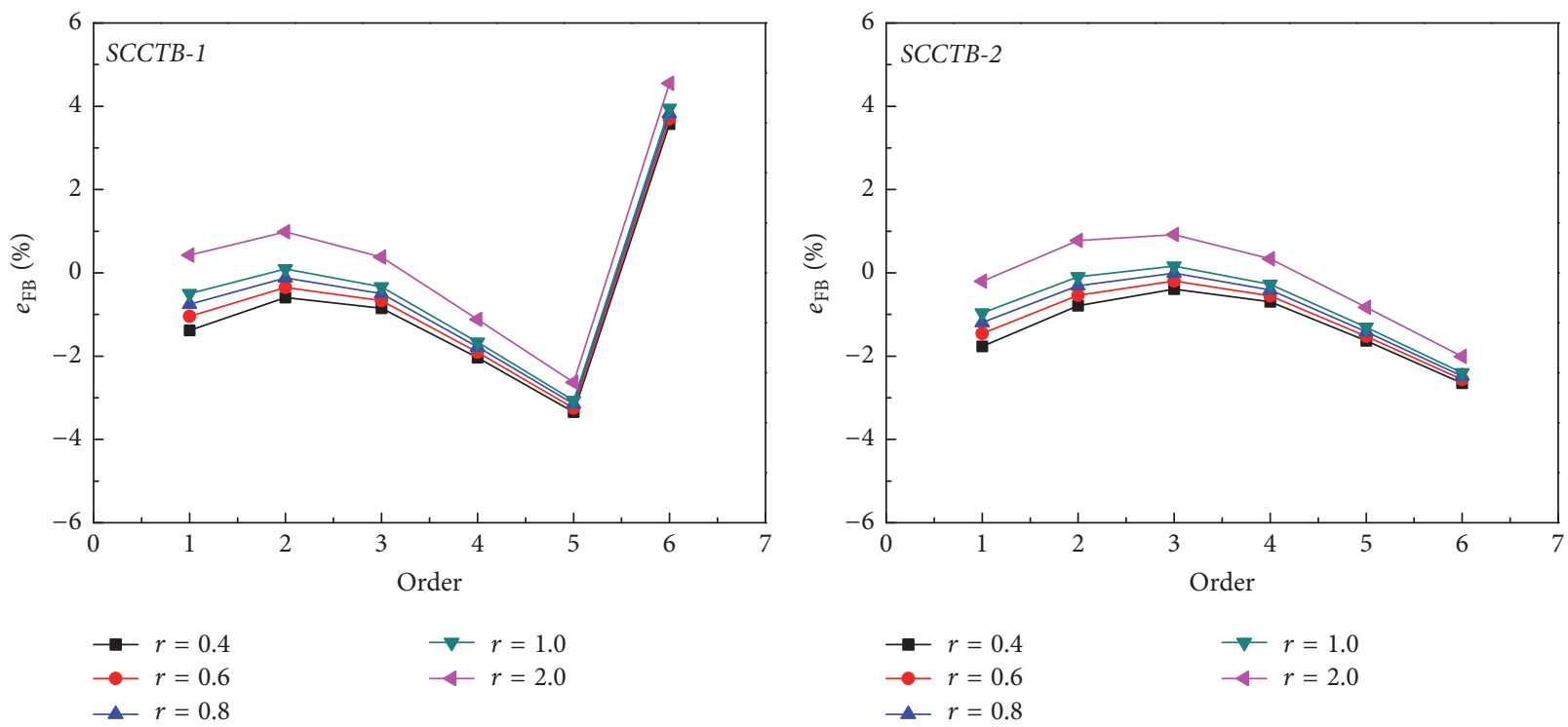

FIGURE 3: Relationship between the calculation errors of FBEM and the mode orders of natural vibration frequency.
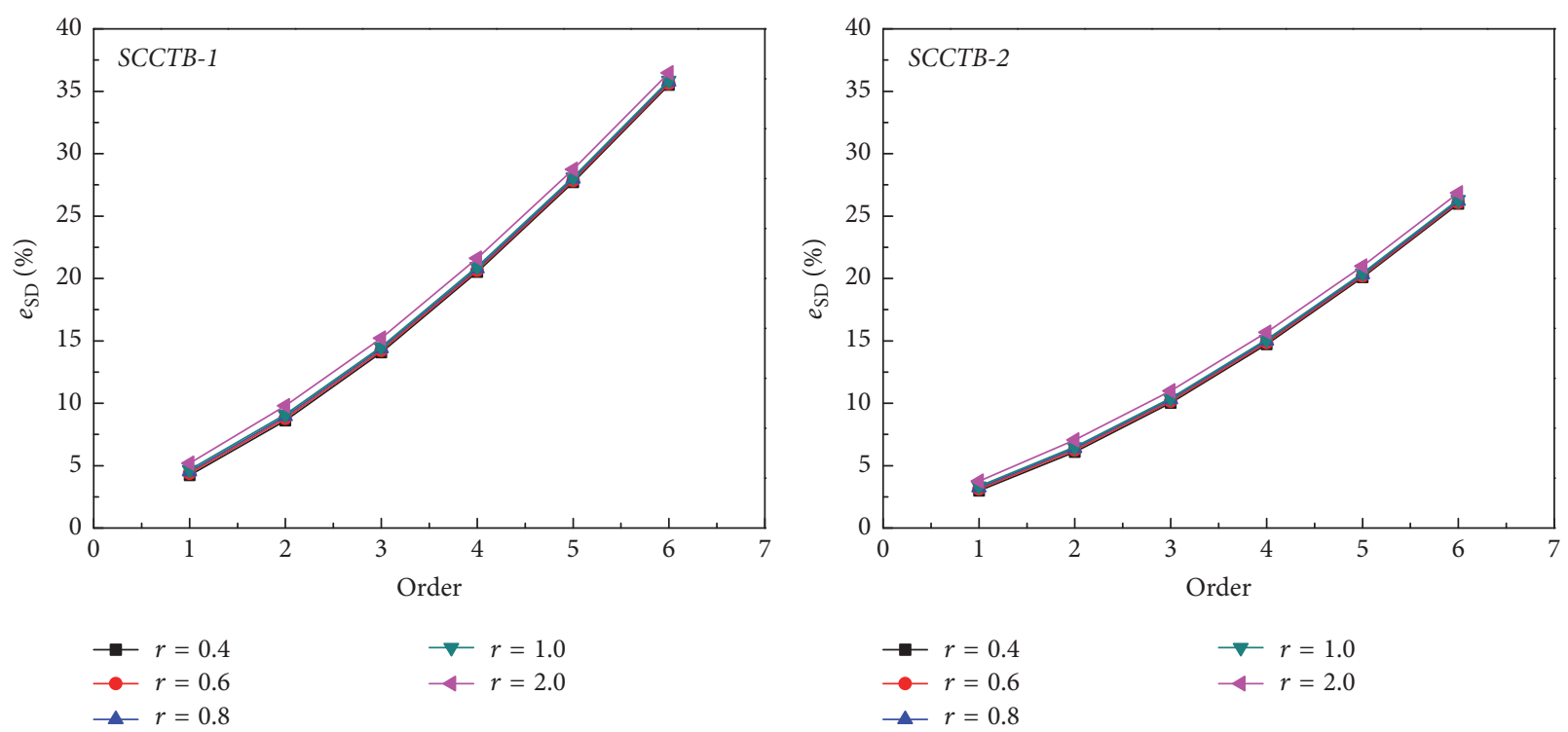

Figure 4: Relationship between the shear deformation effect and the mode orders of natural vibration frequency.

(6) While the interface slip effect on the SCCTB's highorder natural vibration frequency is insignificant, the effect on the SCCTB's low-order natural vibration frequency can be as high as $10.1 \%$. Hence, the effect of interface slip stiffness on the SCCTB's low-order natural vibration frequency cannot be ignored. According to the results of the analyses, this is because SCCTB's section bending stiffness increases with increasing interface slip stiffness, while SCCTB's bending vibration-type of low-order is dominated by the bending deformation caused by the section rotation.

Figures 6 and 7 show the comparison between the first six flexural mode shapes of ANSYS and FBEM models of SCCTB-1 and SCCTB-2. It can be seen that the first six flexural mode shapes of FBEM's calculations agree well with those of the ANSYS's finite element calculations when including the effects of the interface slip, shear deformation, moment of inertia, and many other influencing factors on the SCCTB, which shows that the proposed FBEM model can be used to describe the actual behavior of SCCTBs in flexural vibrations effectively and accurately.

\section{Conclusions}

By including the effects of the interface slip, shear deformation, moment of inertia, and many other influencing factors on SCCTB, and based on Hamilton's principle, the SCCTB element stiffness matrix and mass matrix with cubic Hermite polynomial shape function have been developed. Based on 


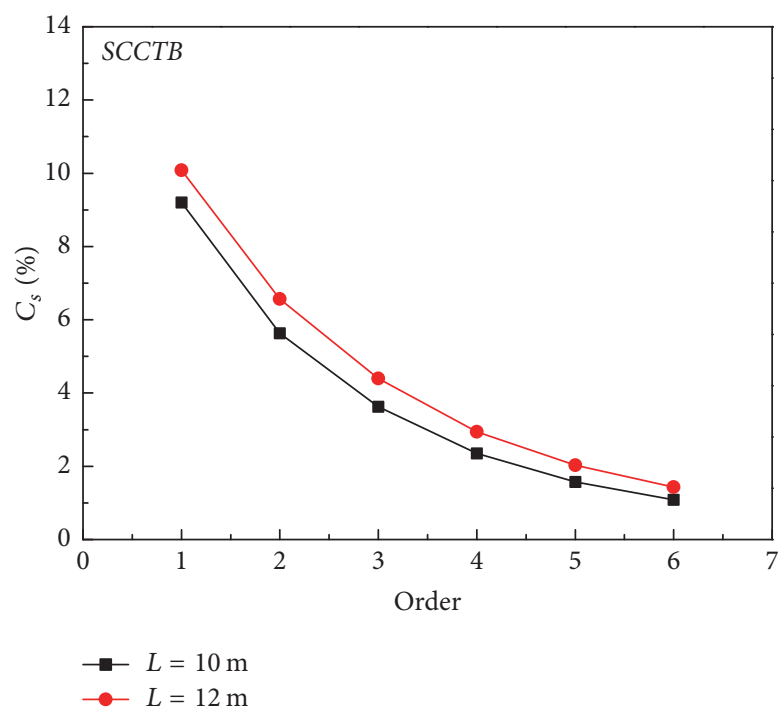

FIGURE 5: Relationship between the interface slip effect and the mode orders of natural vibration frequency.

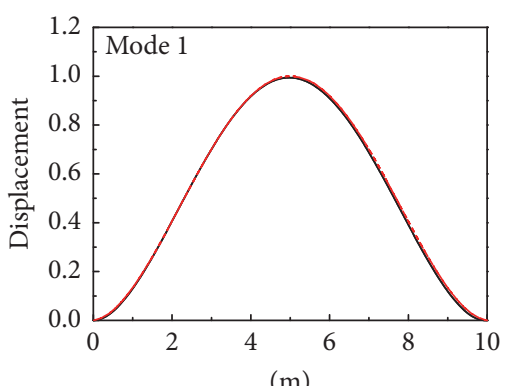

(m)

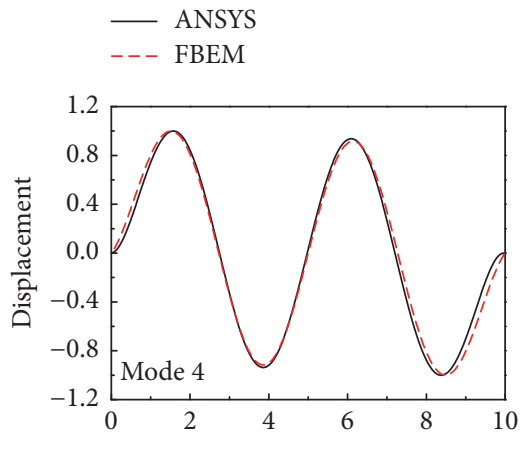

$(\mathrm{m})$

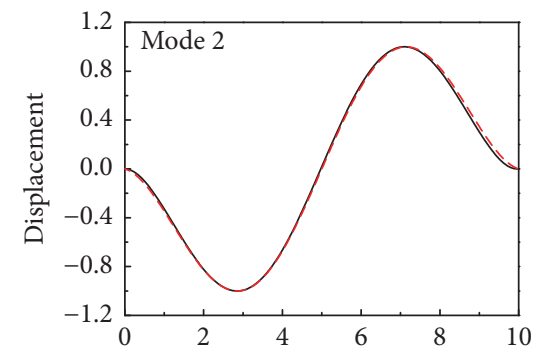

(m)

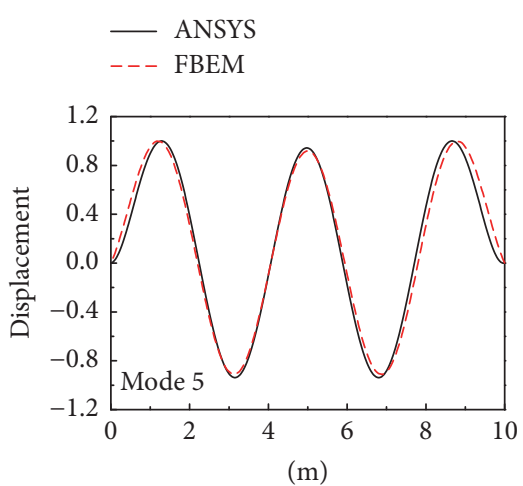

- ANSYS

-- FBEM

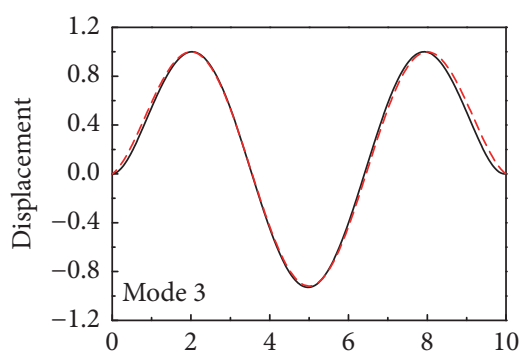

(m)

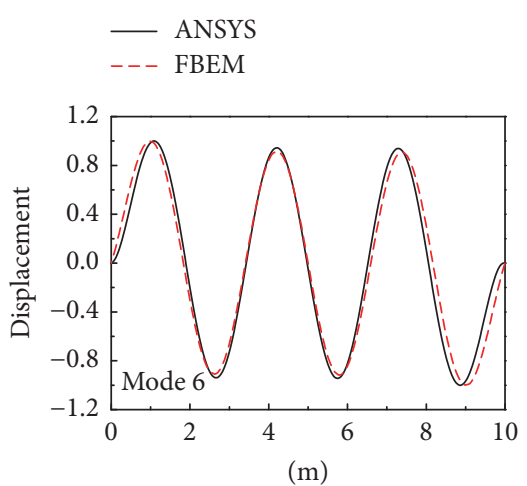

- ANSYS

- - FBEM

FIGURE 6: Comparison between the first six flexural modes of ANSYS and FBEM models of SCCTB-1.

the developed SCCTB element, this study has also developed a FBEM program which can calculate the natural vibration frequency of SCCTBs that are common in the engineering practice. The program has been used to calculate the natural vibration frequencies of several SCCTBs with different spans and different degrees of shear connections. The conclusions are as follows:

(1) The FBEM's calculation results of the natural vibration frequencies of several SCCTBs agree well with the results of ANSYS's finite element calculations. This is an indication that the SССТВ element stiffness matrix and mass matrix developed in this study are effective. Hence, this is a basis for the further applications of the FBEM to the dynamic calculations of SCCTB.

(2) The SCCTB's bending vibration-type of low-order is dominated by the bending deformation caused by the section rotation, and the shear deformation effect 


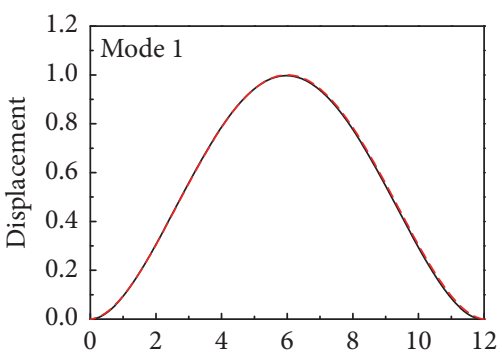

$(\mathrm{m})$

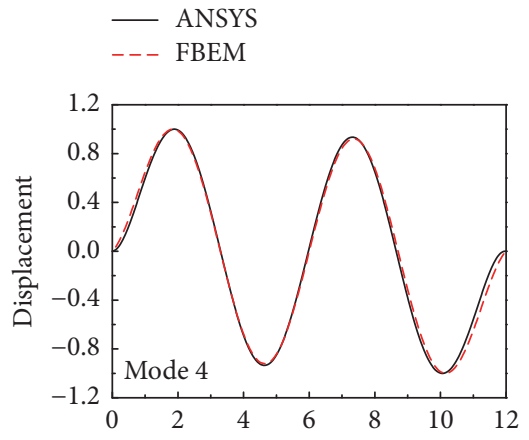

(m)

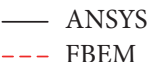

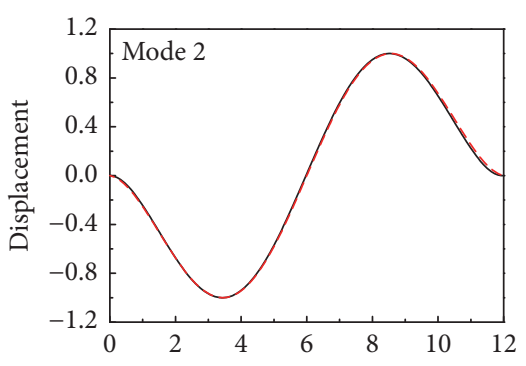

(m)

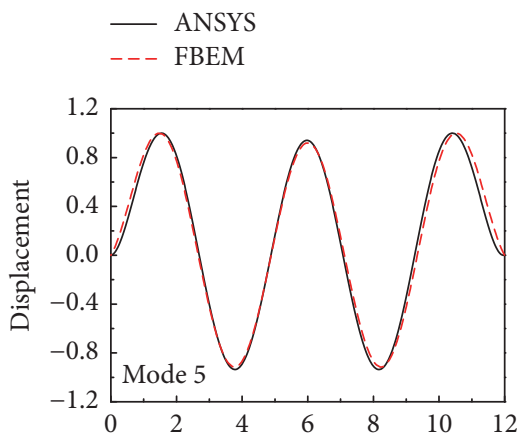

(m)

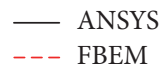

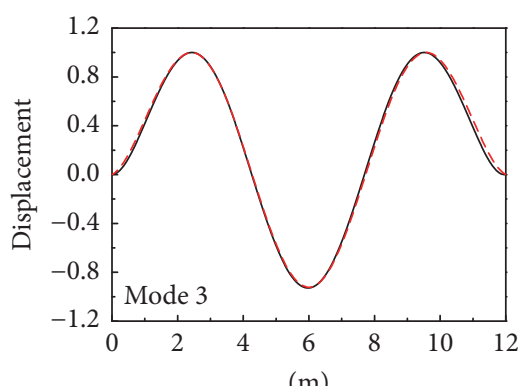

(m)

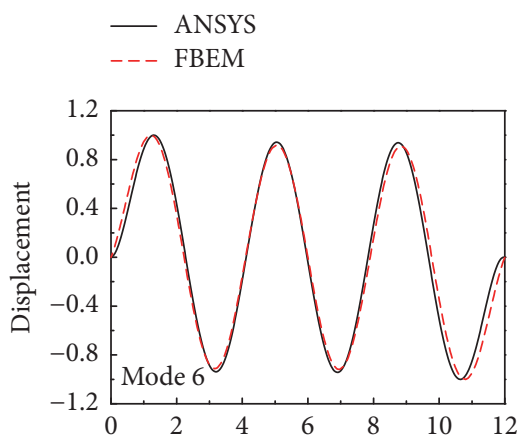

(m)

FIgURE 7: Comparison between the first six flexural modes of ANSYS and FBEM models of SCCTB-2.

of SCCTB's low-order natural vibration frequency is insignificant.

(3) For the SCCTB with high-order natural vibration frequency, the effect of the shear deformation is greater. Hence, the shear deformation effect on the SCCTB's high-order natural vibration frequency cannot be ignored.

(4) Under different degrees of shear connections, the curves for the shear deformation effect and natural vibration frequency order of SCCTBs are overlapped with each other. This is an indication that the effect of the degree of shear connections on SCCTB's shear deformation is not significant.

(5) While the interface slip effect on the SCCTB's highorder natural vibration frequency is insignificant, the effect on the SCCTB's low-order natural vibration frequency is dominated by the section rotation deformation which cannot be ignored.

\section{Conflicts of Interest}

The authors declare that they have no conflicts of interest.

\section{Acknowledgments}

The research described in this paper was financially supported by the National Natural Science Foundation of China (51778630, 51408449 and 51378502), the Special Fund of Strategic Leader in Central South University of China (under
Grant 2016CSU001), and the Fundamental Research Funds for the Central Universities of Central South University of China (2016zzts078).

\section{References}

[1] F.-X. Ding, J. Liu, X.-M. Liu, F.-Q. Guo, and L.-Z. Jiang, "Flexural stiffness of steel-concrete composite beam under positive moment," Steel and Composite Structures, vol. 20, no. 6, pp. 1369-1389, 2016.

[2] J. Liu, F.-X. Ding, X.-M. Liu, and Z.-W. Yu, "Study on flexural capacity of simply supported steel-concrete composite beam," Steel and Composite Structures, vol. 21, no. 4, pp. 829-847, 2016.

[3] J. G. Nie, C. S. Cai, T. R. Zhou, and Y. Li, "Experimental and analytical study of prestressed steel-concrete composite beams considering slip effect," Journal of Structural Engineering, vol. 133, no. 4, pp. 530-540, 2007.

[4] G. Ranzi and A. Zona, "A steel-concrete composite beam model with partial interaction including the shear deformability of the steel component," Engineering Structures, vol. 29, no. 11, pp. 3026-3041, 2007.

[5] A. Chakrabarti, A. H. Sheikh, M. Griffith, and D. J. Oehlers, "Dynamic response of composite beams with partial shear interaction using a higher-order beam theory," Journal of Structural Engineering, vol. 139, no. 1, pp. 47-56, 2013.

[6] W. Zhou and W. Yan, "Refined nonlinear finite element modelling towards ultimate bending moment calculation for concrete composite beams under negative moment," Thin-Walled Structures, vol. 116, pp. 201-211, 2017.

[7] A. Monaco, "Numerical prediction of the shear response of semi-prefabricated steel-concrete trussed beams," Construction and Building Materials, vol. 124, pp. 462-474, 2016. 
[8] G. Monti and F. Petrone, "Shear resisting mechanisms and capacity equations for composite truss beams," Journal of Structural Engineering, vol. 141, 2015, UNSP 0401505212.

[9] G. Campione, P. Colajanni, and A. Monaco, "Analytical evaluation of steel-concrete composite trussed beam shear capacity," Materials and Structures/Materiaux et Constructions, vol. 49, no. 8, pp. 3159-3176, 2016.

[10] B. Giltner and A. Kassimali, "Equivalent beam method for trusses," Practice Periodical on Structural Design and Construction, vol. 5, no. 2, pp. 70-77, 2000.

[11] J. Machacek and M. Cudejko, "Longitudinal shear in composite steel and concrete trusses," Engineering Structures, vol. 31, no. 6, pp. 1313-1320, 2009.

[12] J. Machacek and M. Cudejko, "Composite steel and concrete bridge trusses," Engineering Structures, vol. 33, no. 12, pp. 31363142, 2011.

[13] S. L. Chan and M. Fong, "Experimental and analytical investigations of steel and composite trusses," 2011.

[14] M. Fong, S. L. Chan, and B. Uy, "Advanced design for trusses of steel and concrete-filled tubular sections," Engineering Structures, vol. 33, no. 12, pp. 3162-3171, 2011.

[15] J. Bujnak and A. Bouchair, "Theoretical and Experimental research on Steel-Concrete Composite Truss," 2014.

[16] W. Siekierski, "Analysis of concrete shrinkage along truss bridge with steel-concrete composite deck," Steel and Composite Structures, vol. 20, no. 6, pp. 1237-1257, 2016.

[17] W. Zhou, L. Jiang, Z. Huang, and S. Li, "Flexural natural vibration characteristics of composite beam considering shear deformation and interface slip," Steel and Composite Structures, vol. 20, no. 5, pp. 1023-1042, 2016.

[18] F.-F. Sun and O. S. Bursi, "Displacement-based and two-field mixed variational formulations for composite beams with shear lag," Journal of Engineering Mechanics, vol. 131, no. 2, pp. 199210, 2005.

[19] Z. Wangbao, L. Shu-Jin, J. Lizhong, and Q. Shiqiang, "Vibration analysis of steel-concrete composite box beams considering shear lag and slip," Mathematical Problems in Engineering, vol. 2015, Article ID 601757, 2015. 


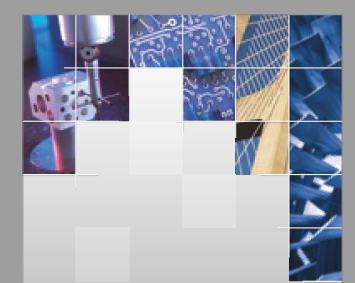

\section{Enfincering}
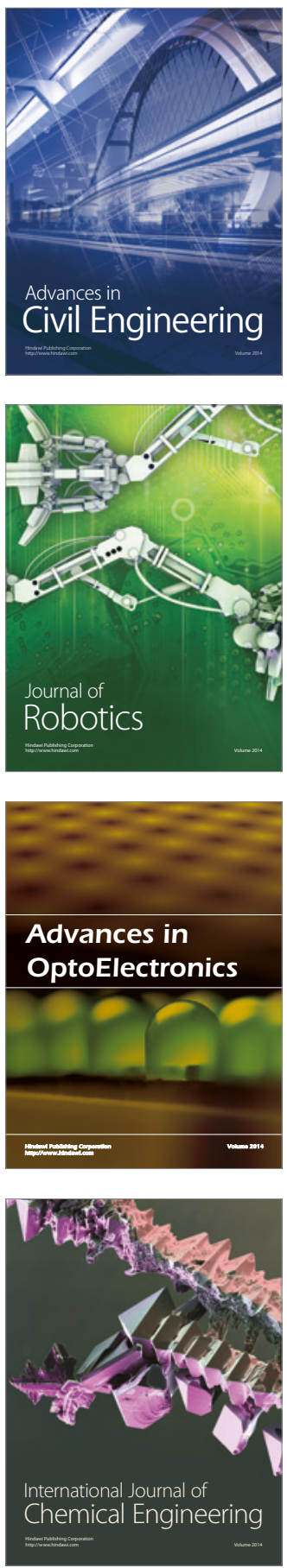

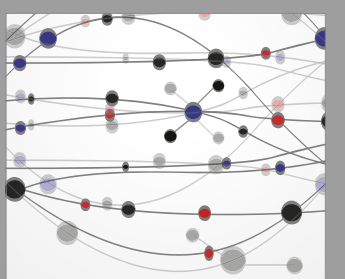

The Scientific World Journal

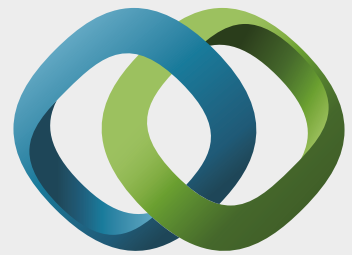

\section{Hindawi}

Submit your manuscripts at

https://www.hindawi.com
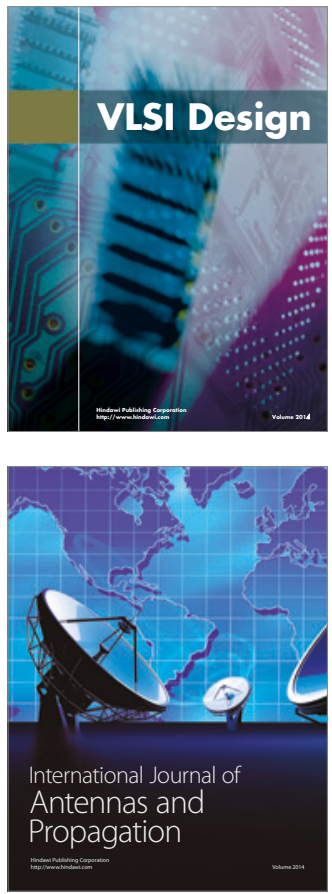

\section{Rotating}

Machinery
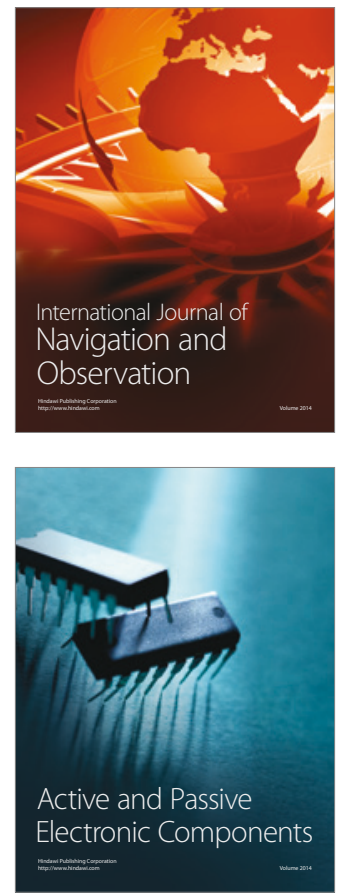
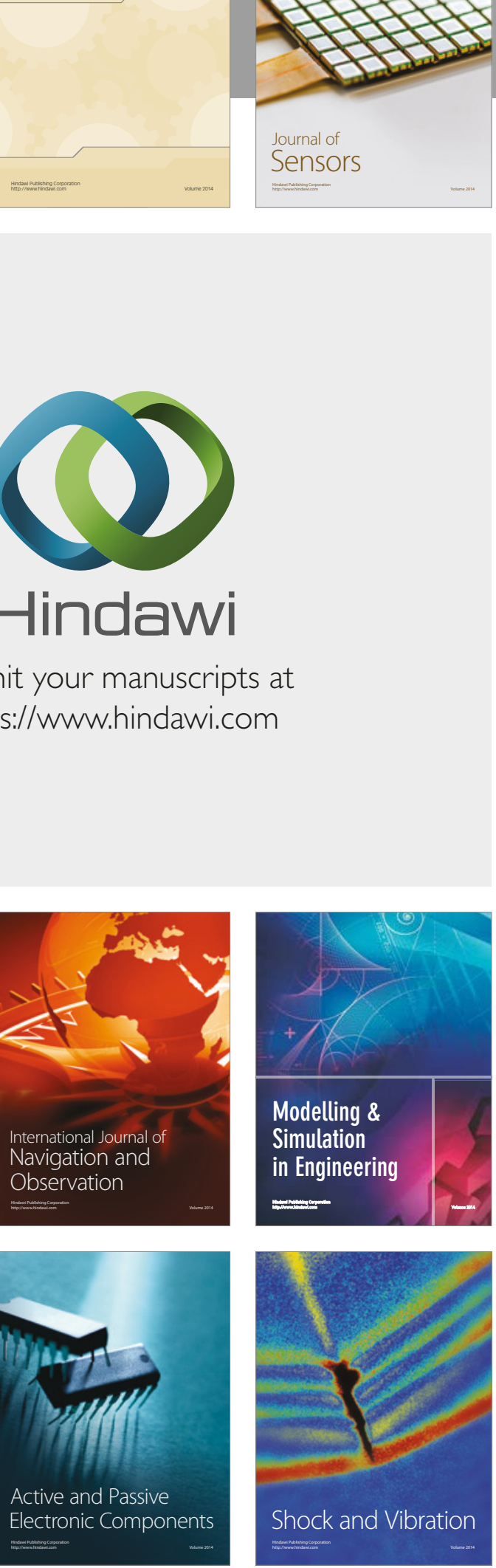
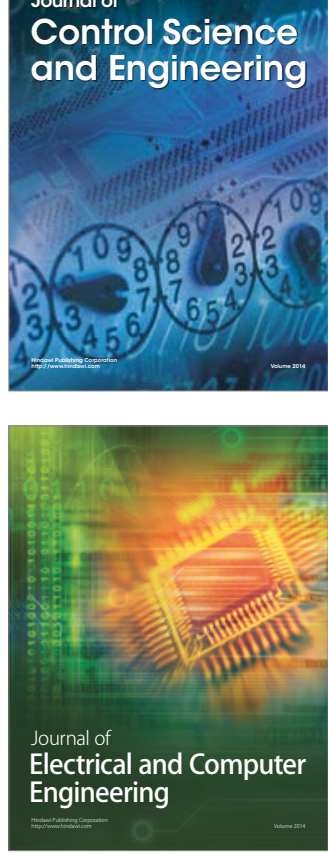

Distributed

Journal of

Control Science

and Engineering
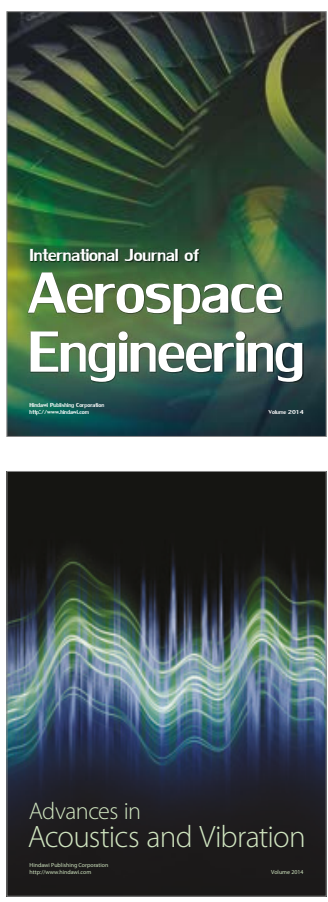

Sensor Networks 